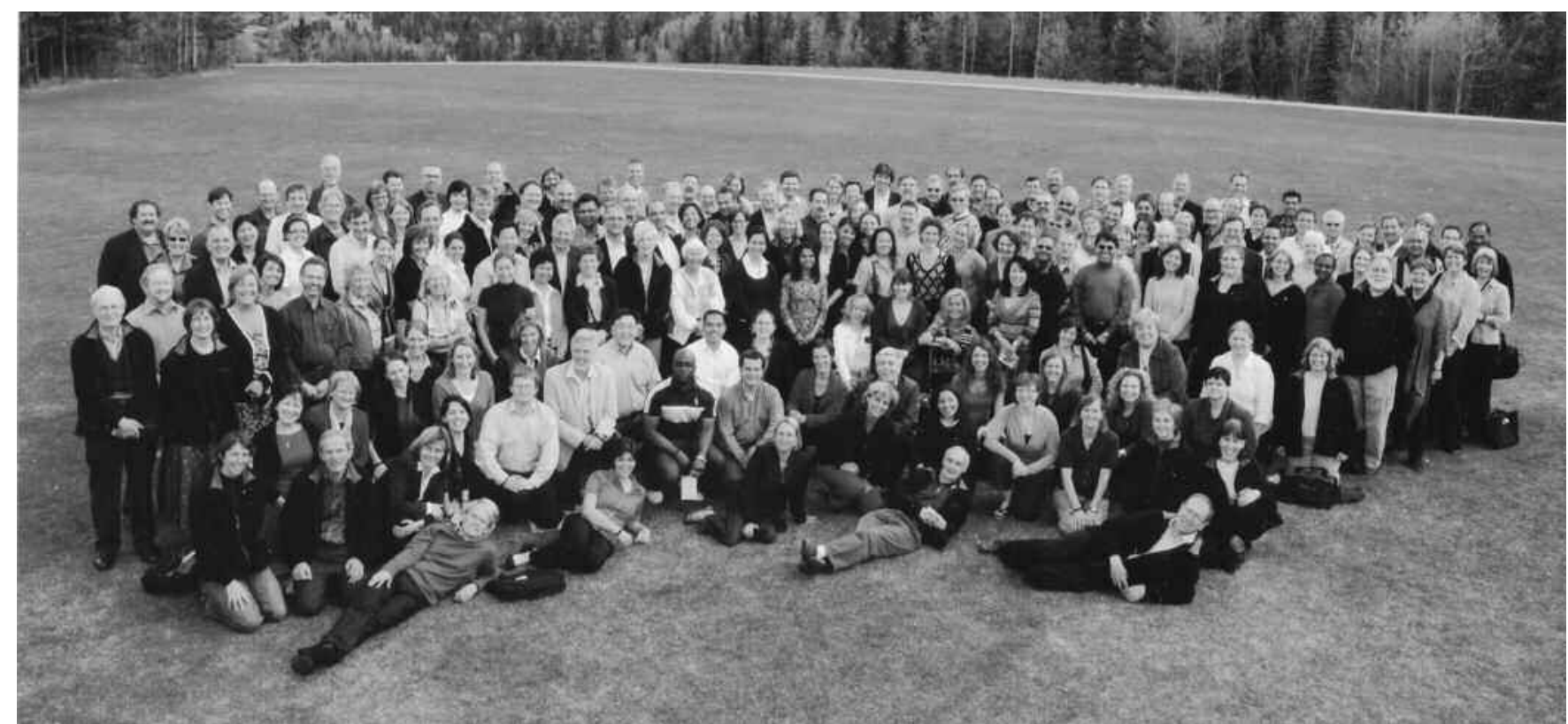

Figure 1. Participants at OMERACT 9, May 27-31, 2008.

Daniel Aletaha, Austria

Rieke Alten, Germany

Dennis Ang, United States

Aslam Anis, Canada

Lesley Arnold, United States

Sibel Aydin, Turkey

Marina Backhaus, Germany

Susan Bartlett, United States

Jennifer Barton, United States

Joan Bathon, United States

Dorcas Beaton, Canada

Jean-Claude Becker, United States

Norma Biln, Canada

Clifton O. Bingham, United States

Paul Bird, Australia

Julius Birnbaum, United States

Maarten Boers, Netherlands

John Bomalaski, United States

Claire Bombardier, Canada

Annelies Boonen, Netherlands

Cornelia Borkhoff, Canada

Pernille Boyesen, Norway

David Boyle, United States

Laurence Bradley, United States

Barry Bresnihan, Ireland

Peter Brooks, Australia

Sait Burak Erer, Turkey

Vivian Bykerk, Canada

Loreto Carmona, Spain

David Cella, United States

Eliza Chakravarty, United States

Ernest Choy, United Kingdom

Robin Christensen, Denmark

Mary Cifaldi, United States

Daniel J. Clauw, United States

Laura Coates, United Kingdom

Bernard Combe, France

Philip Conaghan, United Kingdom
Omar Dabbous, United States

Maria Antonietta D'Agostino, France

Nicola Dalbeth, New Zealand

Cesar Diaz-Torne, Spain

Rozalina Dimitrova, United States

Maxime Dougados, France

Anne Duer-Jensen, Denmark

Kim Dupree Jones, United States

N. Lawrence Edwards, United States

Bo Jannik Ejbjerg, Denmark

Maria Elf, Sweden

Hani El-Gabalawy, Canada

Reuben Escorpizo, United States

Robert Evans, United States

Oliver FitzGerald, Ireland

Jane Freeston, United Kingdom

Daniel Furst, United States

Frederique Gandjbakhch, France

Michael Gauthier, United States

R. Michael Gendreau, United States

Danielle Gerlag, Netherlands

Dafna Gladman, Canada

Jennifer Glass, United States

Duncan Gordon, Canada

Rebecca Grainger, New Zealand

Diane Guinta, United States

Espen Haavardsholm, Norway

Alison Heald, United States

Karen Herlyn, Germany

Sarah Hewlett, United Kingdom

Meilien Ho, United Kingdom

Joanne Homik, Canada

Ben Horgan, Australia

Jos Houbiers, Netherlands

Xingyue Huang, United States

Rod Hughes, United Kingdom

Annamaria Iagnocco, Italy

Leanne Idzerda, Canada

Fredrick Joshua, Australia

Gurjit Kaeley, United States

Richard Kay, United Kingdom
Helen Keen, Australia

Dorothy Keininger, Belgium

John Kirwan, United Kingdom

Jean Claude Lacasse, Canada

Liz Lacasse, Canada

Chinglin Lai, United States

Robert Landewe, Netherlands

Britta Laslo, Canada

Amye Leong, United States

Isabelle Logeart, France

Kathy Longley, United Kingdom

Angeles Lopez-Olivo, United States

Raashid Luqmani, United Kingdom

Anne Lyddiatt, Canada

Patricia MacDonald, United States

Alfred Mahr, France

Yves Mainguy, France

Walter Maksymowych, Canada

Michael Maldonado, United States

Lyn March, Australia

Susan Martin, United States

Juan Antonio Martinez Lopez, Spain

Lynne Matallana, United States

Iris Maurstad, Canada

James May, United States

Fiona McQueen, New Zealand

Philip Mease, United States

Peter Merkel, United States

Patricia Minnock, Ireland

Girish Mody, South Africa

Ingrid Moller Parera, Spain

Pamela Montie, Canada

Jessica Morea, United States

Erin Morris, Canada

Shephard Mpofu, Switzerland

Esperanza Naredo, Spain

Jonathan Nelsen, United States

Tuhina Neogi, United States

Stanton Newman, United Kingdom

Joanna Nicklin, United Kingdom

Annette O'Connor, Canada

Personal non-commercial use only. The Journal of Rheumatology Copyright (c) 2009. All rights reserved. 
Ewa Olech, United States

Richard Osborne, Australia

Mikkel Ostergaard, Denmark

Robert Palmer, United States

Susanne Juhl Pedersen, Denmark

Fernando Perez-Ruiz, Spain

Charles Peterfy, United States

Michael Peterman, United States

Carlos Pineda, Mexico

Christoph Pohl, Germany

Oana Purcaru, Belgium

Emilia Quattrocchi, United Kingdom

Daniel Radecki, United States

Tamara Rader, Canada

Anne-Christine Rat, France

Alan Reynolds, United Kingdom

Pamela Richards, United Kingdom

Daniel Riddle, United States

Christopher Ritchlin, United States

Terence Rooney, United States

Philip Rudge, United Kingdom

I. Jon Russell, United States

Lesley Ann Saketkoo, United States

Tessa Sanderson, United Kingdom
Eric Sasso, United States

Naomi Schlesinger, United States

Wolfgang Schmidt, Germany

Marieke M.J.H Scholte-Voshaar, Netherlands

H. Ralph Schumacher, United States

Philip Seo, United States

John Sharp, United States

Michael Shipley, United Kingdom

Jeffrey Siegel, United States

Stuart Silverman, United States

Lee Simon, United States

Jasvinder Singh, United States

Francisca Sivera Mascaro, Spain

Josef Smolen, Austria

Hugh Smythe, Canada

Alan Solinger, United States

Michael Spaeth, Germany

Randall Stevens, United States

Vibeke Strand, Canada

Anja Strangfeld, Germany

Maria Suarez-Almazor, United States

Silje Watterdal Syversen, Norway

Paul-Peter Tak, Netherlands

Elizabeth Tanjong Ghogomu, Canada
William Taylor, New Zealand

Mark Tengowski, United States

Lene Terslev, Denmark

Karine Toupin April, Canada

Peter Tugwell, Canada

Marleen van de Sande, Netherlands

Desiree van der Heijde, Netherlands

Olivier Vitton, France

Richard Wakefield, United Kingdom

Sharon Waldrop, United States

Brian Walitt, United States

Royce Waltrip, United States

Vivian Welch, Canada

George Wells, Canada

Rawiri Wharemate, New Zealand

David Williams, United States

James Witter, United States

Patrick Wood, United States

Thasia Woodworth, United Kingdom

David Yocum, United States

Wei Zhu, United States

Hans-Rudolf Ziswiler, Switzerland

Gergana Zlateva, United States 


\section{OMERACT 9 - 9th International Consensus Conference on Outcome Measures in Rheumatology Clinical Trials}

OMERACT is an informal international network of health professionals interested in outcome measurement across the spectrum of rheumatology intervention studies. OMERACT strives to improve endpoint outcome measurement through a data-driven, iterative consensus process involving relevant stakeholder groups, who work together on task forces and meet at international gatherings.

The term OMERACT was originally established in 1992 to mean "Outcome Measures in Rheumatoid Arthritis Clinical Trials." Since then the OMERACT initiative has turned into an international informal network. The acronym has been broadened to now stand for "Outcome Measures in Rheumatology." Since the first OMERACT meeting was held in The Netherlands 16 years ago, we have circled the globe 8 times and achieved successes that were previously only dreamed of. This year's conference at the secluded Rocky Mountain Lodge, Kananaskis Village, Alberta, provided the perfect atmosphere for the collegial, interactive, and lively discussions that have characterized OMERACT from its inception (Figure 1).

The OMERACT Executive is delighted at the growth and respect that OMERACT has gained over the years. However, with this unyielding expansion has come the need for creative solutions to the rapid growth caused by this success. One such change is the expansion of the leadership to include a 25-member Steering Group who consult regularly with the executive on difficult issues such as the future structure of OMERACT. Based on their recommendations, OMERACT 9 was restructured to include one module, 4 workshops, and 7 special interest groups meeting at the conference. In addition to these groups, another 7 special interest groups working parallel to the conference presented an update on their progress over the past 2 years.

OMERACT 9 also saw an interesting blend of methods and conditions:

\section{A. Methods}

OMERACT Core Sets relevant to more than one condition:

1. Biomarkers and Surrogate Endpoints

a. Soluble Biomarkers

b. Synovial Tissue Markers

c. Imaging

i. MRI

ii. RA Radiographic Repair / Joint Space Narrowing

iii. Ultrasound

2. Economic Evaluation: Indirect Estimates of QALY's

3. Hip and Knee Arthoplasty

4. International Classification of Function
5. Item Response Theory and Computer Adaptive Testing

6. Patient Perspective

a. Fatigue

b. Psychosocial Measures

c. Sleep

d. Effective Consumer Scale

7. Single-joint Response

8. Virtual Total Articular Replacement

9. Work Productivity

10. Drug Safety

B. Disease/Condition-specific:

1. Fibromyalgia Core Set

2. Flares in Rheumatoid Arthritis

3. Gout Core Set

4. Systemic Sclerosis Core Set

5. Vasculitis Core Set

With the support of both the European League Against Rheumatism and the American College of Rheumatology, the immensely successful fellows program was able to run a third time. We expanded this program at OMERACT 9 to provide young researchers with more new and exciting opportunities to get involved, including a special preconference training day on outcome measurement, poster presentations, and daily fellow discussion forums. These fellows are the future of OMERACT researchers and we are very impressed by their enthusiastic contributions.

Apart from researchers and clinicians, end-user groups are also an integral part of the OMERACT family. From very early on the contributions of both industry and patients in the process were seen as invaluable. Industry supports OMERACT financially through a contribution to the Business Advisory Committee, which serves as a consultation platform; however, the program for OMERACT meetings is decided by the Steering Group. It is hoped that through the productive engagement with industry, outcome measures and concerns raised by the working groups will be taken up in trial design by our industry partners. Patients have been actively involved in OMERACT activities since 2000. Their input is essential to decide on the right measurement tools, and their dedication to the process is an example for us all.

OMERACT 9 was another great success thanks to the hard work and dedication of all involved, especially the group leaders who worked relentlessly to put it all together.

Personal non-commercial use only. The Journal of Rheumatology Copyright @ 2009 . All rights reserved. 
We invite you to read the conference proceedings, which will be published in 3 instalments in the coming issues of The Journal, and will also be freely accessible via the OMERACT Website at www.omeract.org

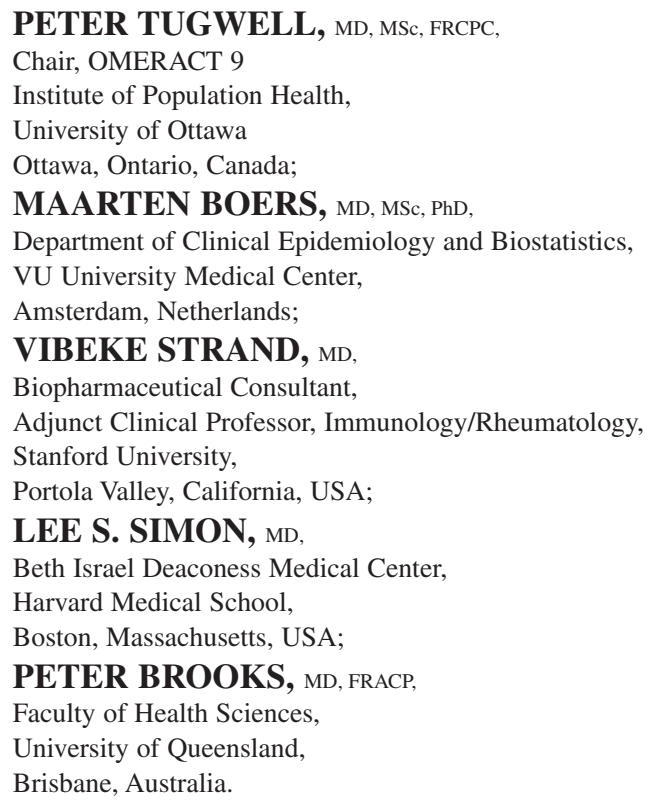

OMERACT 9: International Consensus Conference on Outcome Measures in Rheumatology

\section{ORGANIZING COMMITTEE}

Peter Tugwell, Canada, Chair, OMERACT 9

Maarten Boers, The Netherlands

Peter Brooks, Australia

Lee Simon, USA

Vibeke Strand, USA

\section{OMERACT 9 STEERING GROUP}

Dorcas Beaton
Maxime Dougados
Dan Furst
Sherine Gabriel
Duncan Gordon
Walter Maksymowych
Girish Mody
Pam Richards
Eduardo Samoyoa
Arvind Chopra
Paul Emery
John Kirwan
Dafna Gladman

J Rheumatol 2009;36:1765-8; doi:10.3899/jrheum.090261

\section{ACKNOWLEDGMENT}

Financial support was provided by the following pharmaceutical companies and their subsidiaries: Abbott Labs, USA; Actelion, Switzerland; Alderbio, USA; Allergan, United Kingdom; Amgen, USA; Astellas Pharma, Japan; AstraZeneca, UK; Augurex, Canada; Bristol Myers Squibb, USA; Celgene, USA; Centocor, USA; Combinatorx, USA; Cypress/Forest, USA; Eli Lilly, USA; Encysive, Switzerland; Genentech, USA; Genzyme, USA; GlaxoSmithKline, UK; Hoffmann LaRoche, USA; Jazz Pharmaceuticals, USA; Merck \& Co., USA; Novartis Pharma AG, Switzerland; Organon, Netherlands; Pfizer, USA; Pierre Fabre, France; Savient, USA; TAP Pharmaceuticals, USA; Targeted Genetics, USA; UCB Group, USA; Wyeth, USA; Xoma, USA.

The Organizing Committees wish to thank EULAR and ACR for the bursaries provided to young researchers to partake in the OMERACT program. The OMERACT conferences are only possible through the ongoing commitment of the (co-) chairs and their subgroups of the Modules, workshops, and Special Interest Groups, who provide the science; and a special thank you to Liz Lacasse, Leanne Idzerda, and Q2Q Communications. 